Psychological Medicine, 1986, 16, 775-779

Printed in Great Britain

\title{
The cerebral cortical appearance in depressed subjects
}

\author{
R. J. DOLAN, ${ }^{1}$ S. P. CALLOWAY, P. F. THACKER AND A. H. MANN \\ From the Academic Department of Psychiatry, Royal Free Hospital, London
}

SYNOPSIS This paper describes a comparison of the cerebral cortical appearance of 101 patients with a history of clinical depression and 52 control subjects. An age-related increase in sulcal widening was evident in both groups. However, after controlling for age, the patients were found to differ from control subjects in two respects: they had a greater amount of sulcal widening, most noticeably in the frontal and temporal areas; and there was a positive correlation between increasing sulcal widening and increasing lateral ventricular size not found in the control subjects. Patients with a past history of treatment by electroconvulsive therapy showed more sulcal widening in the parietal and occipital areas than those not so treated.

\section{INTRODUCTION}

The presence of increased lateral cerebral ventricular size has now been established in some patients with schizophrenia and affective disorders (Weinberger et al. $1979 a$; Jacoby \& Levy, 1980; Golden et al. 1980; Dolan et al. 1985). The appearance of the cerebral cortex has been less widely discussed. Widening of the cerebral sulci and fissures has been reported in patients with schizophrenia and affective disorders (Tanaka et al. 1982; Weinberger et al. 1979 b; Nasrallah et al. 1982; Turner et al. 1986), these changes in cortical appearance often correlating with increasing ventricular size. However, Weinberger et al. $(1979 b)$, in a study of schizophrenic patients, failed to find such a correlation between these measures. Thus, whether one or two pathological processes are affecting the brain in these circumstances is not known. The cause of both ventricular enlargement and these cortical changes is similarly obscure. One hypothesis to explain the cortical changes is that they are the result of treatment rather than illness-related phenomena. The possibility that such changes are caused by treatment with electroconvulsive therapy (ECT) has been raised. Weinberger et al.
$(1979 b)$ found more atrophy in schizophrenic patients who had received such treatment;

1 Address for correspondence: Dr R. J. Dolan, Department of Psychological Medicine, The National Hospital for Nervous
Diseases, Queen Square, London WC1N 3BG.
Calloway et al. (1981) found a significant association between the presence of sulcal widening in the frontal lobe and a history of ECT treatment in a group of elderly depressed patients.

The presence and significance of sulcal widening in patients with functional psychiatric disorders need further examination in view of these published reports and the likelihood of these appearances being reported frequently, as more psychiatric patients are investigated by computerized tomographic (CT) scan. This paper reports a comparison of patients with a history of an affective illness and matched non-psychiatric control subjects in terms of the cerebral cortical appearance.

\section{METHOD}

Details of patients and control subjects selected for this study have been described in full elsewhere (Dolan et al. 1985). In summary, the study population comprised 108 patients who met Research Diagnostic Criteria (RDC) for depression (Spitzer et al. 1978) and 52 volunteer normal control subjects of both sexes whose ages ranged between 20 and 79 years. Standard clinical data and psychometric scores were elicited from every participant. Each participant underwent a CT brain scan from which ventricular brain ratios and ratings of cerebral 
sulcal and fissure size were estimated. The latter measure was obtained as follows.

Using pre-defined standards, ratings were made from photographic negatives on a 3-point scale (0-2). Ratings were taken for the following areas: frontal, parietal, occipital and temporal lobes, as well as interhemispheric and Sylvian fissures. The two raters, who were blind to diagnosis, reached a high degree of agreement in their ratings ( $94 \%$ agreement as to the presence of sulcal widening; $81 \%$ complete agreement on the rating). A total cortical score for each subject was obtained by summing the scores from each individual brain region.

\section{STATISTICAL ANALYSIS}

The relationship between clinical status (patient or control), diagnostic status (unipolar or bipolar depression), age (dichotomized $<60$ and $>60$ years of age), and the presence or absence of atrophy were investigated through the use of log-linear or linear-logistic models (see Everitt \& Dunn, 1983). In addition, linear-logistic models for the proportion of subjects with sulcal/fissure widening as a function of treatment group (e.g. ECT $v$. non-ECT $v$. controls) and age group were computed. The model fitted contained main effects of treatment and age group (i.e. there were no significant group-age interactions). Relative risks of atrophy were calculated from the fitted values obtained. All such analyses were carried out using the computer package GLIM (Baker $\&$ Nelder, 1978). The relationship between total cortical score and effects of age and clinical status were examined using the MANOVA procedure (Hull \& Nie, 1981). Before this procedure could be carried out, it was necessary to carry out a square-root transformation of the cortical score in order to normalize the distributions and equalize the variances. The relationships between the cortical score and ventricular size were examined using simple correlation and partial correlation techniques.

\section{RESULTS}

Clinical and demographic details on the patients have been presented in full elsewhere (Dolan et al. 1985). Seven out of the 108 patients declined to have a CT scan and so the following results pertain to the remaining 101 patients
(74 unipolar, 27 bipolar) and 52 normal control subjects. There were no significant differences between the mean ages of the patients $(55 \cdot 2 \pm 14 \cdot 3)$ and of the control subjects $(54 \cdot 0 \pm 14 \cdot 6)$.

\section{(i) Sulcal widening in patients compared with control subjects}

Using a log-linear model, as described above, patients and control subjects were contrasted in terms of regional cortical appearance, the results being presented in Table 1. A significant effect of age on the frequency of a sulcal widening was

Table 1. Regional sulcal widening in 101 patients compared with 52 controls; from fitting log-linear models

\begin{tabular}{lccc}
\hline \hline Region & $\begin{array}{c}\text { Change in } \\
\text { deviance }\end{array}$ & df & $\begin{array}{c}\text { Signifi- } \\
\text { cance }\end{array}$ \\
\hline Frontal & 10.0 & 1 & 0.01 \\
Parietal & 1.8 & 1 & NS \\
Occipital & $2 \cdot 1$ & 1 & NS \\
Temporal & $4 \cdot 8$ & 1 & 0.05 \\
Interhemispheric & $9 \cdot 3$ & 1 & 0.01 \\
Sylvian & $2 \cdot 7$ & 1 & NS \\
\hline \hline
\end{tabular}

noted in all regions examined. Thus it was necessary to allow for this effect in order to demonstrate the significant patient-control differences in the following regions: frontal region $(P<0.01)$; temporal region $(P<0.05)$; and interhemispheric fissure $(P<0.01)$. Patients had a greater frequency of widening in these areas compared with control subjects.

The cortical score was also found to be greater in patients compared with control subjects $(P<0.001)$. This is demonstrated in Table 2 in which the significant age-effect in both patients and controls needed to be included and controlled for in the analysis. There were no effects of sex or diagnostic status (i.e. with regard to uni- or bipolarity) upon the cortical score. Further, there were no significant interactions between the main effects, implying that patient and control differences were independent of age, sex and diagnostic status.

\section{(ii) Relationship of VBR and cortical score in patients and control subjects}

A significant correlation between the VBR and the cortical score was observed both in patients 
Table 2. Analysis of variance of age, sex and clinical status by cortical score in 101 patients and 52 controls

\begin{tabular}{|c|c|c|c|}
\hline & $d f$ & $F$ & $\begin{array}{l}\text { Signifi- } \\
\text { cance }\end{array}$ \\
\hline (A) Main effects & 2 & $40 \cdot 0$ & 0.001 \\
\hline $\begin{array}{l}\text { Age group } \\
\text { Sex }\end{array}$ & 1 & 0.19 & 0.66 \\
\hline $\begin{array}{l}\text { Sex } \\
\text { Unipolars } v \text {. bipolars }\end{array}$ & 1 & 0.1 & 0.78 \\
\hline Patients v. controls & 1 & 12.5 & 0.001 \\
\hline $\begin{array}{l}\text { (B) Interactions } \\
\text { Sex by age group }\end{array}$ & 2 & 1.7 & 0.18 \\
\hline $\begin{array}{l}\text { Sex by age group } \\
\text { Sex by (patients } v \text {. } \\
\text { controls) }\end{array}$ & 1 & 0.32 & 0.72 \\
\hline $\begin{array}{l}\text { Age group by (unipolars } \\
\text { v. bipolars) }\end{array}$ & 2 & 0.37 & 0.69 \\
\hline $\begin{array}{l}\text { Age group by (patients } \\
\text { v. controls) }\end{array}$ & 2 & $2 \cdot 2$ & 0.12 \\
\hline
\end{tabular}

Table 3. Relationships between cortical score $(C S)$; ventricular size (VBR) and age in patients and controls

\begin{tabular}{|c|c|c|c|c|}
\hline & \multicolumn{2}{|c|}{$\begin{array}{c}\text { Patients } \\
(N=101)\end{array}$} & \multicolumn{2}{|c|}{$\begin{array}{l}\text { Controls } \\
(N=52)\end{array}$} \\
\hline & $r$ & $P$ & $r$ & $P$ \\
\hline CS/age & 0.57 & $<0.001$ & 0.71 & $<0.001$ \\
\hline CS/VBR & 0.62 & $<0.001$ & 0.56 & $<0.001$ \\
\hline $\begin{array}{l}\text { CS/VBR } \\
\text { controlling for age }\end{array}$ & 0.41 & $<0.001$ & 0.23 & NS \\
\hline
\end{tabular}

$(r=0.62, P<0.001)$ and in controls $(r=0.56$, $P<0.001$ ). This is shown in Table 3 . However, age was also significantly correlated with both the cortical score and ventricular size in both groups. After controlling for the effect of age, the significant relationship between the cortical score and ventricular size remained in the patients but disappeared among the control subjects.

\section{(iii) Illness characteristics and cortical appearance}

The relationships between age of onset, length of illness, course of illness, number of hospitalizations, and sulcal or fissure size and cortical score were examined. No significant relationships between any of the clinical variables and either of these measures were observed. Alcohol consumption in units of alcohol ( 1 unit of alcohol $=1$ glass of wine/half pint of beer) showed no relationship to either of these CT scan parameters.

\section{(iv) Treament history and cortical atrophy}

The relationships between treatment with, and duration of treatment with, phenothiazines, tricyclics, lithium, benzodiazepines, monoamine oxidase inhibitors, ECT and both regional sulcal inhibitors, ECT and both regional sulcal widening and the cortical score were examined. No relationship between either of these measures was observed for any particular drug. A significant relationship was observed between treatment with ECT and sulcal widening (Table 4). Patients who had received treatment with ECT had a greater frequency of sulcal widening in both the parietal $(P<0.01)$ and occipital $(P<0.05)$ areas. There were no significant effects of treatment with ECT and cortical score. Increasing numbers of applications of ECT were not associated with a greater frequency of regional sulcal or fissure enlargement.

Table 4. Regional sulcal widening in ECT v. non-ECT treated patients; from fitting log-linear models

\begin{tabular}{lccc}
\hline Region & $\begin{array}{c}\text { Change in } \\
\text { deviance }\end{array}$ & df & $\begin{array}{c}\text { Signifi- } \\
\text { cance }\end{array}$ \\
\hline Frontal & $1 \cdot 0$ & 1 & NS \\
Parietal & $7 \cdot 3$ & 1 & $0 \cdot 01$ \\
Occipital & $4 \cdot 1$ & 1 & $0 \cdot 05$ \\
Temporal & $2 \cdot 3$ & 1 & NS \\
Interhemispheric & $1 \cdot 4$ & 1 & NS \\
Sylvian & $3 \cdot 1$ & 1 & NS \\
\hline
\end{tabular}

From the above analysis it would appear that patients with a history of treatment with ECT have a greater likelihood of sulcal widening in the parietal and occipital areas compared with those patients without such a history. To examine this issue further, the relative risks of regional sulcal widening in both patient groups (ECT and non-ECT) compared with control subjects were calculated as described above, using a linearlogistic model. The results of this analysis are presented in Table 5. Patients with a history of previous treatment with ECT had approximately twice the risk of sulcal widening in the parietal area and three times the risk for the occipital area compared with control subjects. For the other cortical regions ECT and non-ECT treated patients had an equal likelihood of sulcal widening. 
Table 5. Estimated risk of regional sulcal widening in ECT treated and non-ECT treated patients relative to controls; from fitted linear-logistic models

\begin{tabular}{lll}
\hline Region & ECT & Non-ECT \\
\hline Frontal & 1.5 & 1.4 \\
Parietal & 1.9 & 0.54 \\
Occipital & $2 \cdot 7$ & 0.63 \\
Temponal & $1 \cdot 3$ & 1.1 \\
Interhemispheric & $1 \cdot 7$ & 1.5 \\
Sylvian & 1.3 & 1.1 \\
\hline
\end{tabular}

\section{DISCUSSION}

The findings reported here are similar to those concerning ventricular appearance (Dolan et al. 1985). The degree of sulcal widening correlated with age in both patients and control subjects. Once the age effect had been discounted, it was evident that patients with a history of affective illness showed significantly greater evidence of sulcal widening than the normal control subjects. These changes were most marked in frontal, temporal and interhemispheric areas of the brain. There was no evidence of association between the presence of these changes and a family history of depression, the duration of depressive illness, the age of onset of illness, the course of illness or exposure to psychotropic medication. However, it appeared that treatment with electroconvulsive therapy was associated with evidence of sulcal widening in the parietal and occipital areas. On analysing the relationship between the ventricular brain ratios with that of the cortical appearance in these subjects, it was discovered that sulcal widening was significantly correlated with ventricular size in the patient but not in the control group.

These findings raise several questions, which cannot yet be fully answered.

(i) Are the findings an artifact arising out of selection bias inherent in the design of the study? The possible effects of selection were discussed in the previous report, where it was argued that the patient selection or other methodological bias could not explain the patient-control differences in ventricular brain ratios. However, it should be recalled that both this and the previous report were of depressed patients whose illness was such that hospital referral and admission were necessary. The findings from the study, therefore, may not pertain to all patients with depression

(ii) Are these findings of sulcal widening no more than evidence of a normal ageing process? Both patients and controls show, as others have reported, greater evidence of sulcal widening with increasing age (Rieder et al. 1983; Ron, 1983). However, these changes have been found to occur to a greater extent among the patient group than the control group and, in the former, the changes appeared to correlate with increasing ventricular brain ratio. For the control subjects there was no correlation between ventricular brain ratio and sulcal widening. One explanation for this patient-control difference is that, among some patients at least, an underlying unitary process is occurring or has occurred at some time in the past that causes both ventricular and cortical changes to appear at the same time, whereas in the control subjects the appearance reffects two possibly independent age-related changes.

(iii) Are the cortical changes reflected in the clinical presentation or course of depressive illness? Sulcal widening was not predicted by the age of onset, a family history of depression, the polarity of depression, or the course of illness. These findings were similar to those for the lateral ventricular size as measured by the ventricular brain ratios. The precise phenomena of the depressive illnesses of the patients and their psychometric status are now being examined in detail and are being related to cortical and ventricular appearances.

(iv) Could these cortical changes reflect previous treatment? The absence of a relationship of the duration of illness and the age of onset to ventricular or cortical changes suggests that they probably antedate the illness. Further, there was no relationship to medication. The finding that the sulci in certain regions of the brain revealed more widening in patients with a history of treatment with ECT could be explained by a direct causal relationship, or a hypothesis that the clinical phenomena of depression in certain patients who were developing or had developed atrophy made it more likely that they were treated by electroconvulsive therapy. The absence of a dose-response relationship between the number of applications of ECT and the cortical changes would appear to rule out a simple causal ex-

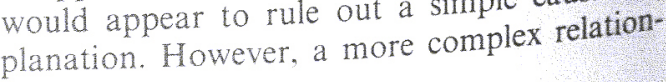


ship between ECT and sulcal widening, involving factors such as individual susceptibility, cannot be ruled out on the basis of this analysis. An analysis of the possible independent effects of unilateral and bilateral ECT was not possible, as most of the patients had received both forms of treatment.

In conclusion, it does appear that certain patients, with a history of affective disorders requiring hospitalization, show a greater degree of ventricular enlargement and sulcal widening than age-matched control subjects. The nature of the changes and their precise meaning is obscure, and there is room for much more detailed research.

\section{REFERENCES}

Andreasen, N. C., Smith, M. R., Jacoby, C. G., Dennert, J. W. \& Olsen, S. A. (1982). Ventricular enlargement in schizophrenia: definition and prevalence. American Joumal of Psychiatry 139 , 292-296.

Baker, R. S. \& Nelder, S. A. (1978). The GLIM System. Release 3: Generalised Linear Interactive Modelling, Royal Statistical Society: London.

Calloway, S. P., Dolan, R. J., Jacoby, R. J. \& Levy, R. (1981). ECT and cerebral atrophy. Acta Psychiatrica Scandinavica 64, 442-445.

Dolan, R. J., Calloway, S.P. \& Mann, A. H. (1985). Cerebral ventricular size in depressed subjects. Psychological Medicine 15, 873-878.

Everitt, B. S. \& Dunn, G. (1983). Advanced Methods of Data
Exploration and Modeling. Hememan Educational Books: London.

Golden, C.J. Moses, J. A. Jr, Zelazowski, R., Graber, B, Zatz L. M. Horvath, T. B. \& Berger, P. A. (1980). Cerebral ventricular size and neuropsychological impaiment in young chronic schizophrenics: measurement by the standardised Luria Nebraska Neuropsychological Battery. Archives of General Psychairy 37. $619-623$

Hall H C \& Nie H. H. (1981). SPSS Update 7..9: New Procedures and Facilities for Releases 7-9. McGraw-Hill: New York

Jacoby, R. J. \& Levy, R. (1980). Computed tomography in the elderly: 3. Affective disonder. British Joumal of Psychatry 136 , $270-275$

Nasrallah, H. A., McCalley-Whitters, M. \& Jacoby, C. G. (1982). Cerebral ventricular enlargement in young manic males: a controlled CT study. Joumal of Affective Disorders 4, 15-19

Rieder, R., Mann, L. S., Weinberger, D. R., van Kammen, D. P. Post, R. M. (1983). Computed tomographic scans in patients with schizophrenia, schizo-affective and bipolar affective disorder. Archives of General Psychiatry 40, 735-739.

Ron, M. A. (1983). The Alcoholic Brain: CT Scan and Psychological Findings. Psychological Medicine. Monograph Supplement 3. Cambridge University Press: Cambridge.

Spitzer, R. L., Endicott, I. \& Robins, E. (1978). Research diagnostic criteria. Rationale and reliability. Archives of General Psychiatry $35,773-782$.

Tanaka, Y., Hazama, H., Fukuhara, T. \& Tsutsui, T. (1982). Computerised tomography of the brain in manic-depressive patients - a controlled study. Folia Psychiatrica et Neurologica Japonica $36,137-144$.

Turner, S. W., Toone, B. K. \& Brett-Jones, J. R. (1986). Computerized tomographic scan changes in early schizophrenia - preliminary findings. Psychological Medicine 16, 219-225.

Weinberger, D. R., Torrey, E. F., Neophytides, A. N. \& Wyatt, R. J. $(1979$ a) Lateral cerebral ventricular enlargement in chronic schizophrenia. Archives of General Psychiatry 36, 735-739

Weinberger, D. R., Torrey, E. F., Neophytides, A. N. \& Wyatt, R. J. $(1979 \mathrm{~b})$. Structural abnormalities in the cerebral cortex of chronic schizophrenia patients. Archives of General Psychatry 36, 935-939. 